TITLE:

\title{
Study on degradation of trigger current level of Superconducting Fault Current Limiter of transformer type
}

\section{AUTHOR(S):}

Fujikawa, K; Shirai, Y; Shiotsu, M; Nitta, T; Hatta, H

\section{CITATION:}

Fujikawa, K ... [et al]. Study on degradation of trigger current level of Superconducting Fault Current Limiter of transformer type. IEEE TRANSACTIONS ON APPLIED SUPERCONDUCTIVITY 2001, 11(1): 2410-2413

ISSUE DATE:

2001-03

URL:

http://hdl.handle.net/2433/50255

\section{RIGHT:}

(c)2001 IEEE. Personal use of this material is permitted. However, permission to reprint/republish this material for advertising or promotional purposes or for creating new collective works for resale or redistribution to servers or lists, or to reuse any copyrighted component of this work in other works must be obtained from the IEEE. 


\title{
Study on Degradation of Trigger Current Level of Superconducting Fault Current Limiter of Transformer Type
}

\author{
Kazuhiro Fujikawa, Yasuyuki Shirai, Masahiro Shiotsu, Tanzo Nitta, and Hiroyuki Hatta
}

\begin{abstract}
A Superconducting Fault Current Limiter (SCFCL) of a transformer type with adjustable trigger current level was proposed in previous works. Basic tests were performed using the trial SCFCL of proposed type. The degradation of the trigger current level of the SCFCL was observed. It is observed that the trigger current level depends on the frequency of the power source. The measured AC loss is about seven times as large as the calculated hysteresis loss and the coupling loss. It is assumed that an excessive loss generated at the short-circuit contact of the secondary winding causes the degradation. The new trial SCFCLs with the improved contact are made. The degradation of the trigger current level does not appear for the new trial SCFCLs.

Index Terms-Current concentration, degradation, nonuniform current distribution. superconducting fault current limiters (SCFCLs), trigger current level,
\end{abstract}

\section{INTRODUCTION}

GUPERCONDUCTING fault current limiters (SCFCLs) Sare expected to reduce the load of circuit breakers. In addition, SCFCLs are expected to improve transient stability of power system. Many studies have been made on the SCFCL of various kinds [1]-[3].

SCFCLs may be installed at both ends of a power line, on tie lines, or for safe operations of superconducting power apparatus. Fault analyses of power system including SCFCLs show that the accuracy of the trigger current level of the SCFCLs should be in several percents.

An SCFCL with adjustable trigger current level is proposed. A trial SCFCL of this type was designed and made. Basic tests for the current limiting and recovery characteristics of the trial SCFCL were carried out [4]-[7]. The degradation of the trigger current level of the trial SCFCL was observed.

In this paper, tests for investigating the frequency characteristics of the trigger current level and the measurements of AC losses are performed. From the results of the tests, the reasons for the degradation of the trigger current level of the trial SCFCL and the method to suppress the degradation are discussed.

\section{SCFCL with Adjustable Trigger Current LEVEL}

The cross sectional view of the trial SCFCL is shown in Fig. 1. The SCFCL consists of two superconducting coils coupled coaxially. The primary and secondary windings are wound on the bobbins of fiber reinforced plastic (FRP).

Manuscript received September 18, 2000. This work was supported in part by the Japan Society for the Promotion of Science under Project No. JSPS-RFTF97P01004.

K. Fujikawa, Y. Shirai and M. Shiotsu are with Department of Energy Science and Technology, Kyoto University, YoshidaHonmachi, Sakyo-ku, Kyoto, 606-8501 Japan. K. Fujikawa's E-mail: fujikawa@pe.energy.kyoto-u.ac.jp.

T. Nitta and H. Hatta are with Department of Electrical Engineering, the University of Tokyo, 7-3-1, Hongo, Bunkyo-ku, Tokyo, 113-8656 Japan. T. Nitta's E-mail: nitta@asc.t.u-tokyo.ac.jp .

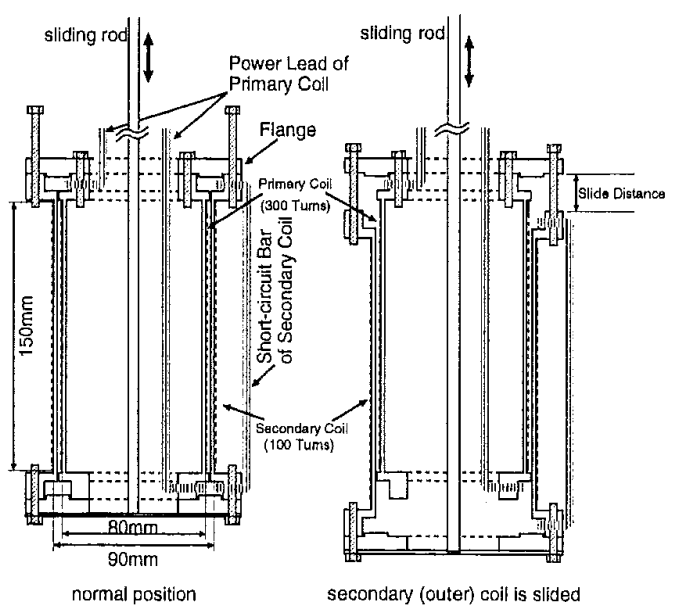

Fig. 1. Cross sectional view of the trial superconducting fault current limiter

The secondary winding is short-circuited by a copper bar. The superconducting wire is in the $\mathrm{V}$-shaped slot of 0.43 $\mathrm{mm}$ depth and coated with epoxy resins. The superconducting wires of the primary and the secondary windings are the same one. The specifications of the superconducting wire for the trial SCFCL are shown in Table I.

A FRP rod is fixed to the bottom of the secondary coil. Only the secondary coil can be slided down by handling the rod outside the cryostat in order to adjust the trigger current level as shown in Fig. 1. The slide distance is defined

TABLE I

SPECIFICATIONS OF SUPERCONDUCTING Wire

\begin{tabular}{|c|c|c|}
\hline Items & & Specification \\
\hline \multirow[t]{10}{*}{ Strand } & Structure & Multifiament \\
\hline & Diameter of strand & $0.126 \mathrm{~mm}$ \\
\hline & Material of matrix & $\mathrm{Cu}-30 \% \mathrm{Ni}$ \\
\hline & & (CuNi:NbTi=4.3:1) \\
\hline & Material of filament & NbTi \\
\hline & Diameter of filament & $0.08 \mu \mathrm{m}$ \\
\hline & Number of flament & 441,575 \\
\hline & Twist pitch & $0.7 \mathrm{~mm}$ \\
\hline & Twist direction & Clockwise(S) \\
\hline & Insulation & None \\
\hline \multirow[t]{5}{*}{ Twisted wire } & Structure & 6 Strands+Core \\
\hline & Material of core & $\mathrm{Cu}-30 \% \mathrm{Ni}$ \\
\hline & Diameter of core & $\sim 0.16 \mathrm{~mm}$ \\
\hline & Twist pitch & $2 \mathrm{~mm}$ \\
\hline & Twist direction & Counterclockwise(Z) \\
\hline \multirow[t]{3}{*}{ Characteristics } & $\begin{array}{l}\text { AC quench current } \\
\qquad\left(I_{q}\right)\end{array}$ & $\begin{array}{l}\sim 150 \text { Arms } \\
(\text { at } 4.2 \mathrm{~K}, 0 \mathrm{~T}) \\
\sim 80 \mathrm{Arms}\end{array}$ \\
\hline & $\begin{array}{l}\text { DC quench current } \\
\qquad\left(I_{c}\right)\end{array}$ & $\begin{array}{r}\sim 240 \stackrel{(\text { at } 4.2 \mathrm{~K}, 2 \mathrm{~T})}{(\text { at } 4.2 \mathrm{~K}, 0 \mathrm{~T})} \\
\end{array}$ \\
\hline & Normal resistance & $\sim 3.18 \Omega / \mathrm{m}$ \\
\hline
\end{tabular}


as the vertical distance between the top of the primary and secondary windings. (See Fig. 1.)

The trigger current level can be adjusted in the range of about ten percents by sliding the secondary coil. When the trigger current level needs to be changed more than ten percents large or small, only the secondary coil can be replaced by another one which has different turns or super-normal transition current.

\section{Discussion on Degradation of Trigger CurRent Level}

The measured trigger current level ( $32.4 \mathrm{Arms}$ ) is about a half of the designed one ( $64.4 \mathrm{Arms}$ ), which is calculated from the AC quench current $I_{q}$ of a short sample of the secondary coil wire (150 Arms) [4]. The measured trigger current level with various slide distance agrees well with that obtained by the electro-magnetic analysis [5] under the assumption that the super-normal transition current of the secondary coil degrades to 75.5 Arms. Therefore, the degradation of the trigger current level of the trial SCFCL is caused by the degradation of the super-normal transition current of the secondary coil.

The reasons that are considered for the degradation of the super-normal transition current would be the following four items.

1. High magnetic field density on the secondary coil

2. Temperature rise of the secondary winding due to the motion of the superconducting wire

3. Temperature rise of the secondary winding due to some losses, such as AC losses, joule heat loss and so on, of the superconducting wire

4. Non-uniform current distribution in the cross section of the superconducting wire, that is, equivalent degradation of the super-normal transition current

If the reason for the degradation is high magnetic field density, the magnetic field density on the secondary coil must be higher than $2 \mathrm{~T}$ referring to the specifications of the superconducting wire (Table I). But, the calculated magnetic field density on the secondary coil is lower than $230 \mathrm{mT}$. The magnetic field density on the secondary coil cannot be the main reason for the degradation.

If the reason for the degradation is the temperature rise of the secondary winding due to the motion of the superconducting wire, the degradation rate of the super-normal transition current would change because the condition of the superconducting wire would change for each time of the current limiting operations. But, the trigger current level does not change for each time of the current limiting operations. The motion of the superconducting wire cannot be the main reason for the degradation.

From the above discussions, it is considered that the temperature rise of the secondary winding due to some losses of the superconducting wire and/or the non-uniform current distribution in the cross section of the superconducting wire might be the reason for the degradation of the supernormal transition current. In order to discuss these reasons of the degradation of the super-normal transition current, the tests for investigating the frequency characteristics of the trigger current level and the measurement of $\mathrm{AC}$ losses were carried out.

\section{Frequency Characteristics of Trigger CurRent LEVEL}

\section{A. Experimental System}

The experimental circuit is shown in Fig. 2. A reactor, a variable frequency power source and the trial SCFCL are connected in series. The inductance $L_{a}$ of the reactor a is $2.13 \mathrm{mH}$.

The variable frequency power source consists of a power amplifier and a function generator. The function generator gives a sinusoidal wave of several frequencies to the power amplifier. The variable frequency power source can be used as not only a voltage source but also a current source. In these tests, the variable frequency power source was used as a voltage source.

\section{B. Test Procedure}

The circuit current $i_{\mathrm{FCL}}$ was increased gradually by varying the gain dial of the power amplifier until the SCFCL turns into the current limiting mode. The current $i_{\mathrm{FCL}}$ at the mode change (from the waiting mode to the current limiting mode) was measured as the trigger current level.

The slide distance was set to be $0 \mathrm{~mm}, 10 \mathrm{~mm}, 20 \mathrm{~mm}$ and $30 \mathrm{~mm}$. The frequency of the power source was set to be $5 \mathrm{~Hz}, 10 \mathrm{~Hz}, 15 \mathrm{~Hz}, 30 \mathrm{~Hz}, 50 \mathrm{~Hz}, 70 \mathrm{~Hz}$ and $100 \mathrm{~Hz}$.

\section{Test Results}

The measured trigger current levels for the frequency are shown in Fig. 3. For every slide distances, it was confirmed that the trigger current level becomes smaller for the larger frequency of the power source.

The trigger current level $I_{\mathrm{TCL}}$ is expressed by $I_{\mathrm{TCL}}=$ $\frac{L_{2}}{M} I_{q}$, where, $L_{2}$ is the self inductance of the secondary coil and $M$ is the mutual inductance [8]. The trigger current level of the SCFCL should be independent of the frequency. Therefore, the temperature rise of the secondary winding, which is dependent on the frequency, might cause the

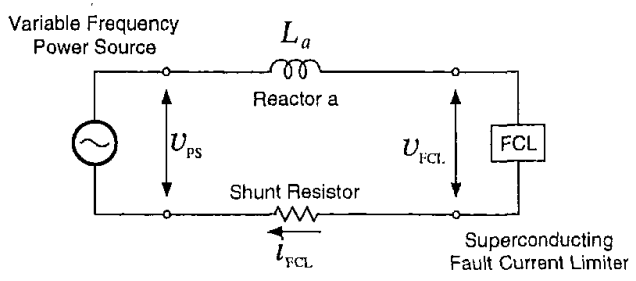

Fig. 2. The experimental circuit for the tests

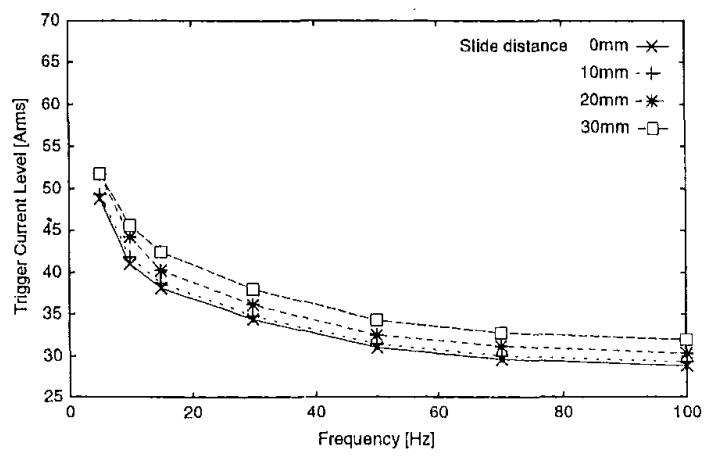

Fig. 3. The trigger current level of the trial SCFCL versus the frequency of the power source 
degradation of the super-normal transition current of the secondary winding. The losses which are dependent on the frequency ( $\mathrm{AC}$ losses) would be generated in the secondary winding, and this might be the reason for the degradation of the trigger current level of the trial SCFCL. In order to measure the amount of the $\mathrm{AC}$ losses, the volume of helium gas evaporated was measured.

\section{Measurement of AC losses}

\section{A. Experimental System}

The helium gas outlet of the cryostat, in which the SCFCL is, was connected to a gas flow meter via a heat exchanger which warms the helium gas up to the room temperature. The output voltage of the gas flow meter is proportional to the gas flow rate. The voltage signal from the gas flow meter was recorded.

The experimental circuit is shown in Fig. 2.

\section{B. Test Procedure}

The variable frequency power source was used as the current source. The circuit current was kept to be 20 Arms constant. The slide distance was set to be $0 \mathrm{~mm}$. The frequency of the power source was set to be $5 \mathrm{~Hz}, 10 \mathrm{~Hz}$, $15 \mathrm{~Hz}, 30 \mathrm{~Hz}, 50 \mathrm{~Hz}, 70 \mathrm{~Hz}, 100 \mathrm{~Hz}$ and $120 \mathrm{~Hz}$.

The volume of the helium gas flowing out was measured by the gas flow meter for several frequencies of the circuit current. The measurement was started a few minutes after the frequency of the power source was changed.

\section{Test Results}

The measured volume of the helium gas flowing out versus the frequency are shown in Fig. 4. The frequency was increased from $5 \mathrm{~Hz}$ to $120 \mathrm{~Hz}$, and then decreased from $120 \mathrm{~Hz}$ to $5 \mathrm{~Hz}$.

The measured gas flow increases in almost proportion to the frequency. The evaporated helium gas at $0 \mathrm{~Hz}$ is due to the heats into the cryostat and the joule loss by the resistance of the power lead. The amount of the increment is caused by the AC losses.

Some hysteresis effect can be seen for increasing and decreasing the frequency. This would be due to the time delay of the response of the gas output for the heat generation.

From Fig. 4, the volume of the helium gas evaporated in the cryostat is $6.975 \mathrm{\ell} / \mathrm{min}$. at $0 \mathrm{~Hz}$, and $7.230 \mathrm{\ell} / \mathrm{min}$. at $50 \mathrm{~Hz}$. The volume of the helium gas evaporated by $\mathrm{AC}$ losses is $0.255 \ell / \mathrm{min} .\left(=4.25 \times 10^{-6} \mathrm{~m}^{3} / \mathrm{s}\right)$ at $50 \mathrm{~Hz}$.

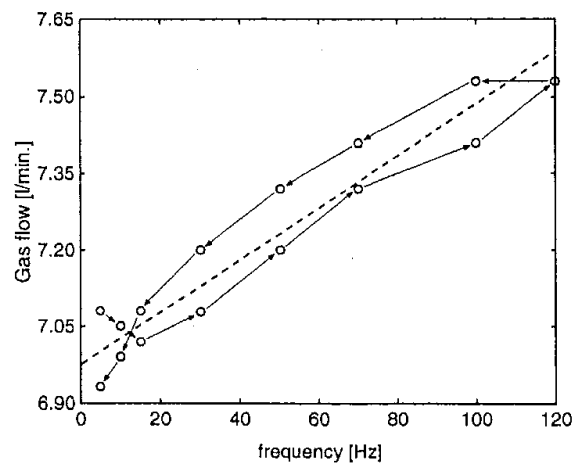

Fig. 4. The volume of the helium gas flowing out of the cryostat versus the frequency of the power source
The amount of AC losses can be roughly calculated from the volume of the helium gas evaporated by $\mathrm{AC}$ losses. The vaporization heat of helium is $20.416 \mathrm{~kJ} / \mathrm{kg}$ at $4.2 \mathrm{~K}$ and $1 \mathrm{~atm}$. The density of helium gas is $0.1785 \mathrm{~kg} / \mathrm{m}^{3}$ at $300 \mathrm{~K}$ and $1 \mathrm{~atm}$. Therefore, the amount of $\mathrm{AC}$ losses is $1.549 \times 10^{-2} \mathrm{~W}$, which is the sum of AC losses of the primary and secondary coils.

\section{Discussion}

Major AC losses of the superconducting wire consist of a hysteresis loss and a coupling loss. The hysteresis loss and the coupling loss per unit volume are calculated by using the equations shown in [9] from the specifications of the superconducting wire.

The calculated hysteresis loss and the coupling loss per unit volume are $255 \mathrm{~W} / \mathrm{m}^{3}$ and $17.3 \mathrm{~W} / \mathrm{m}^{3}$ for the frequency of $50 \mathrm{~Hz}$, respectively. The total AC loss per unit volume is evaluated to be about $272 \mathrm{~W} / \mathrm{m}^{3}$.

Because the total cross sectional area of six strands is $0.0748 \times 10^{-6} \mathrm{~m}^{2}$, superconducting wire length of the primary coil is $75.4 \mathrm{~m}$ and that of the secondary coil is 28.3 $\mathrm{m}$, the total volume of strands is $7.76 \times 10^{-6} \mathrm{~m}^{3}$. Therefore, the total AC loss of the trial SCFCL is evaluated to be about $2.11 \times 10^{-3} \mathrm{~W}$ for the frequency of $50 \mathrm{~Hz}$.

The measured total AC loss is about seven times of the calculated one. It is expected that another factor generates the excessive loss in the trial SCFCL and the loss causes the degradation of super-normal transition current of the secondary winding.

\section{Discussion on Current Concentration}

It was reported that the $\mathrm{AC}$ quench current of a superconducting magnet degrades due to the joule loss by current redistribution at the contact to the power lead [10]. It is assumed that the excessive loss of the trial SCFCL would be caused by the current redistribution among filaments of the secondary winding nearby the contact to the short-circuit copper bar. The current redistribution occurs in order to clear the non-uniform current distribution in the secondary coil wire due to the current concentration at the contact to the short-circuit copper bar.

In the short-circuit copper bar, the current of each filaments is not equal due to the skin effect, and the $\mathrm{AC}$ current flows near the surface of the short-circuit bar. On the other hand, in the superconducting wire of the secondary winding, the current of each filaments is almost equal because the filaments and the strands are twisted so that they are geometrically uniform.

Let us consider the contact between the superconducting wire of the secondary winding and the short-circuit copper bar of the trial SCFCL. The diameter of the superconducting wire is about $0.4 \mathrm{~mm}$. The cross section of the short-circuit bar near the contact is about $5 \mathrm{~mm} \times 4 \mathrm{~mm}$. Therefore, the AC current which flows near the surface of the short-circuit bar rushes into the superconducting wire of the secondary winding at the point of the contact as shown in Fig. 5 (current concentration).

Because of the resistance of the matrix of the strand, the non-uniform current distribution in the strand of the secondary winding occurs nearby the contact to the shortcircuit copper bar. Then, the current redistribution among filaments occurs in the secondary winding. The current flows across the filaments through the CuNi-matrix whose resistance is large, and joule loss is generated due to the current. 


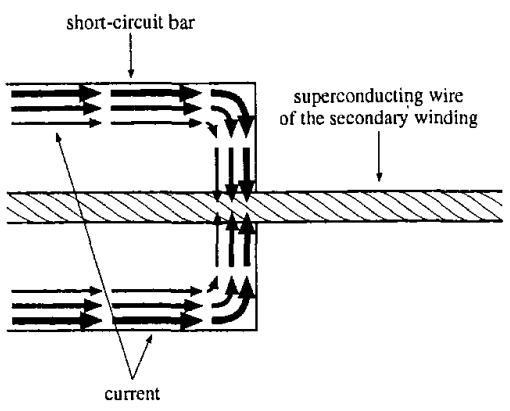

Fig. 5. The contact between the superconducting wire of the secondary winding and the short-circuit copper bar of the trial SCFCL

It is expected that the joule heat loss is produced by the current through CuNi-matrix and raises the temperature of the superconducting wire nearby the contact to the shortcircuit copper bar. The temperature rise of the secondary winding can be one of the reasons for the degradation of the super-normal transition current of the secondary coil.

Because of the current concentration at the contact, the current density of the superconducting wire at the contact is expected to be higher than that of the superconducting wire far from the contact, which is equal to the average current density in the superconducting wire of the secondary winding. That is, the current density at the contact reaches the critical current density even if the current of the secondary winding is smaller than the AC quench current $I_{q}$. The super-normal transition current degrades. Therefore, the current concentration also would be one of the reasons for the degradation of the super-normal transition current of the secondary coil.

In order to suppress the degradation of the trigger current level, new three-phase trial SCFCLs of the proposed type with the improved contact were manufactured. The improved contact shown in Fig. 6 is designed so that the current concentration at the contact is suppressed. The tests for investigating the trigger current levels of the new trial SCFCLs were carried out. The measured trigger current levels of the new trial SCFCLs are about 81 Arms, 90 Arms and 87 Arms, respectively. The measured trigger current levels are in the range of about $\pm 5 \%$ around the designed one (85.7 Arms)[11]. The measured trigger current levels of the new trial SCFCLs almost agree with the designed one. The improved contact can suppress the degradation of the trigger current level. It is pointed out that the degradation is caused by the design of the shortcircuit contact of the secondary winding.

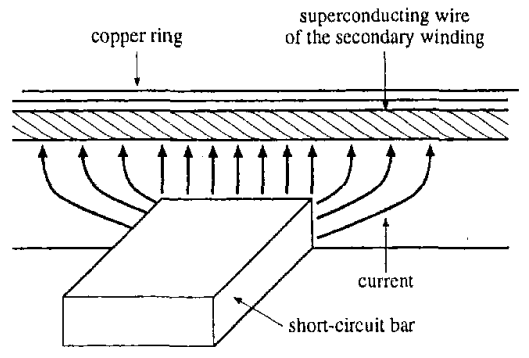

Fig. 6. The improved contact of the new trial SCFCLs

\section{CONCluSion}

The tests of investigating the frequency characteristics of the trigger current level and the measurements of the $\mathrm{AC}$ losses were carried out. It is observed that the trigger current level depends on the frequency of the power source. The measured $\mathrm{AC}$ loss is about seven times as large as the calculated hysteresis loss and the coupling loss.

From these experimantal results, it is assumed that an excessive loss generated at the short-circuit contact of the secondary winding. The new trial SCFCLs with the improved contact are made. The degradation of the trigger current level does not appear for the new trial SCFCLs.

The trigger current level of a transformer type SCFCL is determined by the super-normal transition current of the secondary winding, which is a short-circuited superconducting coil. Even if the degradation of the super-normal transition current appears only in a small part of the wire, the trigger current level of the SCFCL is determined by the degraded super-normal transition current.

When a transformer type SCFCL is made, it is important to manufacture the secondary coil (the short-circuited superconducting coil) so that the conditions of the whole winding of the coil is uniform thermally and magnetically.

\section{ACKNOWLEDGMENT}

The authors would like to acknowledge the suggestions of Mr. Toru Okazaki (Sumitomo Electric Industries, Ltd.).

\section{REFERENCES}

[1] T. Hara, T. Okuma, T. Yamamoto, D. Ito, K. Tasaki and K. Tsurunaga, "Development of a new $6.6 \mathrm{kV} / 1500 \mathrm{~A}$ class superconducting fault current limiter for electric power systems," IEEE Trans. on Power Delivery, vol. 8, No. 1, pp. 182-192, Jan. 1993.

2] M. Ichikawa and M. Okazaki, "A magnetic shielding type superconducting fault current limiter using a Bi2212 thick film cylinder," IEEE Trans. on Applied Superconductivity, vol. 5, No. 2 der, '1067-1070, Jun. 1995

[3] B. Gromoll, G. Ries, W. Schmidt, H.-P. Krämer, P. Kummeth and H.-W. Neumüller, "Resistive current limiter with YBCO films," IEEE Trans. on Applied Superconductivity, vol. 7, No. 2, pp. 828831, Jun. 1997.

[4] K. Fujikawa, Y. Shirai, T. Nishikawa, 'T. Nitta, M. Fukunish and T. Shibata, "Experimental study on superconducting fault current limiter with adjustable trigger current level" Proceedings of 15th International Conference on Magnet Technology (MT15), (Beijing, October 1997), pp. 571-574, Sep. 1998, Science Press.

[5] K. Fujikawa, Y. Shirai, T. Nitta, K. Hagiwara and T. Shibata, "Experimental study on adjustability of superconducting fault current limiter with adjustable trigger current level," IEEE fault current limiter with adjustable trigger current level, Jun. 1999

[6] Y. Shirai, K. Fujikawa, T. Nitta, K. Hagiwara and T. Shibata, "Recovery characteristics of fault current limiter with adjustable trigger current level," IEEE Trans. on Applied Superconductivity, trigger current level,

7] Y. Shirai, K. Fujikawa, M. Shiotsu, T. Ikejiri, T. Nitta and H Hatta, "Study on recovery time of superconducting fault current limiter with adjustable trigger current level," to be presented at Applied Superconductivity Conference 2000 (ASC 2000), Virginia Beach, Sep. 2000.

[8] H. Hatta T. Nitta, Y Shirai, K. Fujikawa and T. Ikejiri: "Experimental Estimation on Characteristics of Superconducting Fault ings of Technical Group on Power Engineering of I.E.E. Japan, Sep. 1999, No. PE-99-149, (in Japanese).

[9] Martin N. Wilson: Superconducting magnets, pp. 162-182, Oxford University Press, 1982

[10] Thends of development of $A C$ superconducting technology, Technical report of I.E.E. Japan, vol. 599, pp. 35, I.E.E. Japan, Aug 1996 (in Japanese)

[11] H. Hatta, T. Nitta, S. Muroya, Y. Shirai, K. Fujikawa, T. Ikejiri and T. Kitagawa: "Experimental studies on adjustment of trigger current level of 3-phase superconducting fault current limiter" 2000 National Convention Record of I.E.E. Japan, Mar. 2000 No. 5-218, (in Japanese). 